\title{
A Educação Permanente em Saúde no Serviço de Atendimento Móvel de Urgência ${ }^{1}$
}

\author{
Andrielly Barros Silva \\ Acadêmica do Curso de Bacharel em Enfermagem da Faculdade Estácio de Macapá, Brasil \\ $\triangle$ andri_andry@hotmail.com \\ Gabriel Miranda Lopes \\ Acadêmico do curso de Bacharel em Enfermagem da Faculdade Estácio de Macapá, Brasil. \\ $\checkmark$ mirandalopes@gmail.com \\ Kamila Maria Penna Batista \\ Acadêmica do curso de Bacharel em Enfermagem da Faculdade Estácio de Macapá, Brasil. \\ $\square$ kamilapenn@gmail.com \\ Mônica Cristina da Silva Castro \\ Graduada em Licenciatura Plena e Bacharel em Enfermagem pela Universidade Federal do Amapá. \\ Especialista em Unidade de Terapia Intensiva. Mestre em Saúde da Família. \\ Docente na Faculdade Estácio de Macapá no Curso de Enfermagem \\ $\square$ monica.cristinacastro@hotmail.com
}

Recebido em 13 de outubro de 2017

Aceito em 24 de abril de 2018

\begin{abstract}
Resumo:
A Educação Permanente é uma estratégia Política Nacional implantada pelo Ministério da Saúde em 2004, visando a capacitação dos profissionais nos serviços de saúde. Esta pesquisa teve como objetivo, identificar por meio da literatura, as atividades relacionadas à Educação Permanente em Saúde que o Serviço de Atendimento Móvel de Urgência desenvolve no âmbito da prática assistencial. Trata-se de uma Revisão Integrativa da Literatura com recorte temporal de 2012 a 2017 e busca de artigos nas bases de dados da Biblioteca Virtual em Saúde por meio de periódicos na Scientific Electronic Library Online - SCIELO, Literatura Latino-Americana e do Caribe em Ciências da Saúde - LILACS, Base de dados de enfermagem - BDENF e Literatura Internacional em Ciências da Saúde - MEDLINE. Na análise dos dados emergiram três categorias temáticas, sendo apresentadas nos resultados: a primeira categoria - a importância da educação permanente em saúde nos serviços de saúde. Segunda categoria - as estratégias e atividades de educação permanente em saúde. E a terceira categoria - a percepção dos profissionais sobre o processo de educação permanente no Serviço Móvel de Urgência. Obtém-se como resultado a falta de conhecimentos dos profissionais sobre Educação Permanente em Saúde e a importância de conhecer, incorporar e desenvolver atividades voltadas para aperfeiçoamento dos serviços móveis de urgência. Conclui-se que este instrumento é de grande valia para todos os profissionais por gerar mudanças no processo de trabalho dos setores e assim obter uma melhora nas práticas de saúde oferecidas a população diante da realidade local.
\end{abstract}

Palavras-chave: Educação, Capacitação, Serviços Médicos de Emergência, Aprendizagem.

\section{Permanent health education in the urgent mobile care services}

\section{Abstract:}

The permanent education is a National Policy strategy implemented by the Ministry of Health in 2004, aimed at training professionals in the health services. The primary objective of this research is to

${ }^{1}$ Artigo derivado de um Trabalho de Conclusão de Curso. 
identify, through the literature, the activities related to the Permanent Education in Health that the Mobile Emergency Care Service develops within the scope of care practice. This is a bibliographical research based on an Integrative Review of Literature with a temporal cut from 2012 to 2017 and search of articles in the databases of the Virtual Health Library through journals in the Scientific Electronic Library Online - SCIELO, Latin American and Caribbean Literature in Health Sciences LILACS, Nursing Database - BDENF and International Literature in Health Sciences - MEDLINE. In the analysis of the data emerged three thematic categories, being presented in the results: the first category - the importance of the permanent education in health in the health services. Second category - the strategies and activities of permanent education in health. And the third category the perception of professionals about the process of permanent education in SAMU. The result is a lack of professional knowledge about EPS and the importance of incorporating, knowing and developing activities aimed at improving mobile emergency services. It is concluded that this instrument is of great value to all professionals for generating changes in the work process of the sectors and there a improvement in the health practices offered to the population before the local reality.

Keywords: Education, Training, Emergency Medical Services, Learning.

\section{La educación permanente en salud en el servicio de atención móvil de urgencia}

\section{Resumen:}

La Educación Permanente es una estrategia política nacional implantada por el Ministerio de Salud en 2004, con vistas a la capacitación de los profesionales en los servicios de salud. La investigación tiene como objetivo primario, identificar a través de la literatura, las actividades relacionadas a la Educación Permanente en Salud que el Servicio de Atención Móvil de Urgencia desarrolla en el ámbito de la práctica asistencial. Se trata de una investigación bibliográfica a partir de una Revisión Integrativa de la Literatura con recorte temporal de 2012 a 2017 y búsqueda de artículos en las bases de datos de la Biblioteca Virtual en Salud por medio de periódicos en la Scientific Electronic Library Online - SCIELO, Literatura Latino- América Latina y el Caribe en Ciencias de la Salud - LILACS, Base de datos de enfermería - BDENF y Literatura Internacional en Ciencias de la Salud - MEDLINE. En el análisis de los datos surgieron tres categorías temáticas, siendo presentadas en los resultados: la primera categoría - la importancia de la educación permanente en salud en los servicios de salud. Segunda categoría - las estrategias y actividades de educación permanente en salud. Y la tercera categoría - la percepción de los profesionales sobre el proceso de educación permanente en el SAMU. Se toman como resultado la falta de conocimientos de los profesionales sobre EPS y la importancia de incorporar, conocer y desarrollar actividades orientadas a la mejora de los servicios móviles de urgencia. Se concluye que este instrumento es de gran valor para todos los profesionales por generar cambios en el proceso de trabajo de los sectores y así haber un cambio en las prácticas de salud ofrecidas a la población ante la realidad local.

Palabras clave: Educación, Capacitación, Servicios Médicos de Urgencia, Aprendizaje.

\section{INTRODUÇÃO}

A Educação Permanente em Saúde (EPS) é uma estratégia político-pedagógica que visa reconceituar os processos de capacitação de profissionais nos serviços de saúde. Representa um conjunto de atividades que englobam desde a capacitação emergencial até a formação mais estruturada, viabilizando a operação do serviço no sentido de sua produtividade com 
eficiência e eficácia (BRASIL, 2004).

A EPS busca incorporar os princípios e valores do SUS através da renovação do modelo de atenção, intensificando a promoção e prevenção de saúde por meio dos processos educativos e produtivos (BRASIL, 2010).

Em 2004, foi implantada a Política Nacional de Educação Permanente em Saúde (PNEPS) pela Portaria nº 198, na qual o Ministério da Saúde adota medidas no sentido de discutir e orientar mudanças na formação dos profissionais da área da saúde. Nesse contexto, faz-se necessário aplicar o programa de EPS ao Serviço de Atendimento Móvel de Urgência, com o objetivo de transformar a prática profissional dos profissionais socorristas.

O Serviço de Atendimento Móvel de Urgência - SAMU, foi instituído no ano de 2003, pelo Ministério da Saúde, através da Portaria n.ํำ 1.864 e redefinido pela Portaria n. 1.010 de 2012, com o objetivo de socorrer precocemente vítimas de quaisquer agravos a saúde através do acionamento de uma Central de Regulação das Urgências pelo número 192, com envio de veículo com equipes capacitadas livrando-as de sofrimento, sequelas ou a morte.

O SAMU realiza atendimento de pedidos de socorro de urgência ou emergência de qualquer natureza, mas principalmente atendimento a pacientes acometidos por quadros agudos ou crônicos, traumatizados em acidentes automobilísticos e violência doméstica ou urbana. Os profissionais qualificados para este atendimento inclui médicos, enfermeiros, técnicos ou auxiliares de enfermagem e condutores locomovidos através de ambulâncias de unidade de suporte básica ou avançada, aeromédico, embarcação, motolância e veículo de intervenção rápida.

Diante do exposto, o estudo justifica-se pela importância de conhecer como é introduzido a EPS no Serviço de Atendimento Móvel de Urgência, enfatizando as práticas de educação permanente dos profissionais como recurso para aprimoramento técnico e científico.

Conforme as observações realizadas nos artigos científicos e no cotidiano da vida social e acadêmica, podemos perceber que existem fragilidades nas práticas diárias das equipes do SAMU. Tal fato gerou a inquietação em saber, como estes profissionais realizam as atividades relacionadas a EPS diante dos problemas encontrados nas suas reais condições de trabalho totalmente diferente do que se aprende nas academias. 
Portanto, o estudo tem como perguntas norteadoras as indagações: Qual a importância da educação permanente em saúde nos Serviços de Urgência e Emergência? Quais as estratégias de EPS utilizadas com os profissionais dentro do contexto e realidade vivenciada pelo serviço? E qual a percepção dos profissionais sobre o processo de educação permanente no SAMU?

Este trabalho possui relevância acadêmica, pois existe carência de estudos que discutam esse contexto e desta forma ajudar os acadêmicos da área da saúde, em formação profissional, visando a ampliação de novos saberes. Além disso, o estudo pode contribuir na relevância das políticas públicas de saúde, uma vez que poderão ser detectadas dificuldades e/ou fragilidades, e estas servirão de subsídios para reflexões críticas e construtivas ao SAMU e gerar recomendações para os gestores locais de saúde do município.

Dessa forma, o artigo tem como objetivo primário identificar através da literatura, quais são as atividades relacionadas à Educação Permanente em Saúde que o Serviço de Atendimento Móvel de Urgência desenvolve no âmbito da prática assistencial. E como objetivos secundários: identificar através das produções científicas, a percepção dos profissionais sobre o processo de educação permanente no SAMU e descrever quais as atividades educativas e as estratégias utilizadas pelas equipes do SAMU para promover a educação permanente em saúde como prática transformadora do processo de trabalho.

\section{METODOLOGIA}

Trata-se de uma Revisão Integrativa da Literatura (RIL), com síntese de vários estudos bibliográficos publicados e baseados na experiência vivenciada pelos autores (SOUZA, SILVA e CARVALHO, 2010).

Rocha (2014), cita Paulo Freire na qual diz, que a educação permanente em saúde é importante por ser um agente de modificações na educação e posteriormente nas práticas dos profissionais envolvidos, tornando-o autônomo intelectualmente e ainda mais responsável. Logo, o estudo baseou-se na importância da educação permanente em saúde nos serviços de urgência e emergência.

A pesquisa atendeu às seis etapas da RIL, descritas a seguir: 
Etapa 1 - identificação do tema e seleção da hipótese ou questão de pesquisa: A revisão integrativa permite identificar, analisar e sintetizar resultados do estudo a partir da questão norteadora do tema proposto (BOTELHO, CUNHA e MACEDO, 2011). Nesse sentido, a pergunta norteadora da pesquisa foi: Qual a importância da educação permanente em saúde nos Serviços de Urgência e Emergência? Quais as estratégias de EPS utilizadas com os profissionais dentro do contexto e realidade vivenciada pelo serviço? E qual a percepção dos profissionais sobre o processo de educação permanente no SAMU?

Etapa 2 - Seleção da amostra (estudos): A busca em base de dados deve ser ampla e diversificada, contemplando a procura em bases eletrônicas, busca manual em periódicos e as referências descritas nos estudos selecionados (GALVÃO, SAWADA e TREVIZAN, 2004).

Nesta etapa foi feita a seleção de artigos científicos disponibilizados eletronicamente em bancos de dados da Biblioteca Virtual em Saúde (BVS), Scientific Electronic Library (SCIELO), Literatura Latino-Americana e do Caribe em Ciências da Saúde (LILACS), Base de Dados em Enfermagem (BDENF) e Medical Literature Analysis and Retrieval System on-line (MEDLINE) utilizando os seguintes descritores ou palavras-chave: Educação, Capacitação, Serviços Médicos de Emergência, Aprendizagem.

Etapa 3 - Coleta de dados e definição das características: Foram utilizadas referências bibliográficas publicadas com um recorte temporal dos anos de 2012 a 2017.

Os critérios de inclusão considerados na busca foram os seguintes: artigos com idioma em português, de qualquer modalidade de estudo, disponíveis na íntegra e gratuitamente e que contemplassem em seus conteúdos, títulos e/ou resumos e/ou descritores ou palavraschave: educação, capacitação, serviços médicos de emergência, aprendizagem.

Foram excluídos artigos disponibilizados somente em idioma inglês e espanhol, publicação de artigos com apenas resumos, as duplicidades e artigos com ano de publicação inferior a 2012.

$\mathrm{Na}$ coleta de dados foram encontradas 500 publicações dentre as plataformas de pesquisas das bases de dados. Foram excluídos: 420 artigos na análise do título, 19 artigos após 
análise das palavras chave e 52 artigos após a leitura na íntegra, por não enquadrarem nos objetivos da pesquisa e recorte temporal. Diante das análises dos materiais selecionados foi possível identificar apenas 9 publicações de acordo com os requisitos exigida pela pesquisa.

Etapa 4 - avaliação dos estudos incluídos na revisão integrativa: Análoga à análise dos dados das pesquisas convencionais, esta fase demanda uma abordagem organizada para ponderar o rigor e as características de cada estudo (SILVEIRA, 2005; URSI e GAVÃO, 2006).

Desse modo, após leitura detalhada, sumarização e interpretação das informações extraídas dos artigos revisados, foram definidas três categorias temáticas que trazem a síntese do conhecimento abordado pelos estudos: 1- A Importância da Educação Permanente em Saúde no Serviço de Atendimento Móvel de Urgência, 2- As Estratégias e Atividades de Educação Permanente em Saúde e 3 - A Percepção dos Profissionais sobre o Processo de Educação Permanente no SAMU.

Etapas 5 e 6 - discussão dos resultados e apresentação da revisão integrativa: $\mathrm{Na}$ $5^{\text {a }}$ etapa, a começar da interpretação e síntese dos resultados, contrasta-se os dados evidenciados na análise dos artigos ao referencial teórico. Além de identificar prováveis lacunas do conhecimento, é possível delinear prioridades para estudos futuros (URSI e GAVÃO, 2006).

Compete nesta etapa realizar a interpretação e a análise dos resultados obtidos, salientando as conclusões e inferências do pesquisador permitindo a construção de um texto de fácil compreensão no intuito de responder à pergunta que norteia a pesquisa.

$\mathrm{Na} 6^{a}$ etapa a apresentação da revisão deve ser clara e na integra para permitir ao leitor avaliar criticamente os resultados. Deve conter, então, informações pertinentes e detalhadas, baseadas em metodologias contextualizadas, sem omitir qualquer evidência relacionada (SILVEIRA, 2005; URSI e GAVÃO, 2006).

Por se tratar de uma pesquisa de revisão integrativa da literatura não houve o envolvimento direto ou indireto de seres humanos, o projeto foi encaminhado para análise e emissão de parecer do Comitê de Ética em Pesquisa da Faculdade Estácio de Macapá, no 
município de Macapá/AP, e obteve, com êxito, o certificado de isenção, sob o Protocolo $\mathrm{N}^{\circ}$ 103/2017 e cumprimento das normas institucionais, atendendo o que preconiza a Resolução CNS n॰ 466/12 do Conselho Nacional de Saúde, sendo fiel às bibliografias consultadas. Ressalta-se que a formatação do artigo seguiu os critérios e normas da Associação Brasileira de Normas Técnicas (ABNT).

\section{RESULTADOS}

Para apresentação dos resultados foi realizado leitura minuciosa dos artigos científicos selecionados que emergiram em três categorias temáticas, demonstrados com auxílio de tabelas definidas a seguir:

\section{Categoria 1: A Importância da Educação Permanente em Saúde no Serviço de Atendimento Móvel de Urgência}

Esta categoria foi abordada por 2 (dois) estudos, correspondendo à 22,22\% do total, sendo estes destacados na tabela 1.

O Ministério da Saúde (MS) lançou a PNEPS para tornar possível as mudanças necessárias na formação e desenvolvimento dos trabalhadores da saúde. Em 2014, o MS, reafirmou os conceitos de PNEPS, descrevendo-a como uma aprendizagem no local de serviço, onde há uma união entre o aprender e o ensinar, possibilitando assim uma transformação nas práticas dos trabalhadores da saúde (LAPROVITA et al., 2016).

De acordo com Laprovita et al. (2012), a EPS é indispensável para as equipes do serviço de atendimento móvel de urgência e emergência, pois ela dá subsídios para o profissional entender a especificidade de cada região, comunidade, usuário e trabalhador envolvido neste processo. 
Tabela 1 - caracterização dos estudos sobre "A importância da educação permanente em saúde no serviço de atendimento móvel de urgência".

\begin{tabular}{|c|c|c|c|c|c|}
\hline $\begin{array}{l}\text { ARTIGO/ } \\
\text { AUTORES }\end{array}$ & PERIÓDICO & ANO & $\begin{array}{c}\text { TIPO DE } \\
\text { PESQUISA }\end{array}$ & OBJETIVO & RESULTADO \\
\hline $\begin{array}{l}\text { Educação } \\
\text { permanente } \\
\text { no } \\
\text { atendimento } \\
\text { pré-hospitalar } \\
\text { móvel: } \\
\text { perspectiva de } \\
\text { Emerson } \\
\text { Merhy. } \\
\text { LAPROVITA, D.; } \\
\text { FERNANDES F. } \\
\text { C.; ALMEIDA } \\
\text { L.P; CORVINO, } \\
\text { M.P.F.; } \\
\text { CORTEZ, E. A.; } \\
\text { BRAGA, A. L.S. }\end{array}$ & $\begin{array}{l}\text { Biblioteca } \\
\text { Virtual em } \\
\text { Saúde - BVS / } \\
\text { Base de dados } \\
\text { de } \\
\text { enfermagem - } \\
\text { BDENF }\end{array}$ & 2016 & $\begin{array}{l}\text { Estudo } \\
\text { descritivo, } \\
\text { tipo análise } \\
\text { reflexiva. }\end{array}$ & $\begin{array}{l}\text { Refletir, teórica e } \\
\text { filosoficamente, } \\
\text { sobre a importância } \\
\text { da educação } \\
\text { permanente como } \\
\text { ação } \\
\text { transformadora das } \\
\text { práticas individuais } \\
\text { e coletivas no } \\
\text { serviço de } \\
\text { atendimento pré- } \\
\text { hospitalar móvel de } \\
\text { urgência, sob a } \\
\text { perspectiva de } \\
\text { Emerson Merhy. }\end{array}$ & $\begin{array}{l}\text { Revela que a } \\
\text { educação } \\
\text { permanente } \\
\text { acontece no } \\
\text { cotidiano da prática, } \\
\text { em um movimento } \\
\text { constante de } \\
\text { formação no mundo } \\
\text { do trabalho. o } \\
\text { processo de } \\
\text { formação do } \\
\text { trabalhador ocorre } \\
\text { no mundo do } \\
\text { trabalho e o próprio } \\
\text { ato do trabalho e é } \\
\text { um ato formativo no } \\
\text { atendimento pré- } \\
\text { hospitalar. }\end{array}$ \\
\hline $\begin{array}{l}\text { Políticas de } \\
\text { educação } \\
\text { permanente e } \\
\text { formação em } \\
\text { saúde: uma } \\
\text { análise } \\
\text { documental*. } \\
\text { CELEDÔNIO, R. } \\
\text { M.; JORGE, M. S. } \\
\text { B.; SANTOS, D. } \\
\text { C. M.; FREITAS, } \\
\text { C. H. A., } \\
\text { AQUINO, F. O. T. } \\
\text { P. }\end{array}$ & $\begin{array}{l}\text { Rede de } \\
\text { Revistas } \\
\text { Científicas da } \\
\text { América } \\
\text { Latina, Caribe, } \\
\text { Espanha e } \\
\text { Portugal - } \\
\text { REDALIC }\end{array}$ & 2012 & $\begin{array}{l}\text { Análise } \\
\text { Documental }\end{array}$ & $\begin{array}{l}\text { Analisar publicações } \\
\text { em periódicos de } \\
\text { saúde e documentos } \\
\text { do Ministério da } \\
\text { Saúde acerca da } \\
\text { política nacional de } \\
\text { educação } \\
\text { permanente e as } \\
\text { ações desenvolvidas } \\
\text { a partir de } 2003 \text {, } \\
\text { com a criação da } \\
\text { Secretaria de Gestão } \\
\text { do Trabalho e } \\
\text { Educação na Saúde } \\
\text { (SGTES). }\end{array}$ & \begin{tabular}{|l|} 
Apesar das \\
necessidades de \\
mudança, a \\
formação dos \\
profissionais \\
mostra-se como um \\
desafio, pois se \\
configura com a \\
complexidade da \\
gestão, do serviço e \\
do ensino com as \\
políticas \\
intergovernamentais \\
entre os Ministérios \\
da Saúde e Educação.
\end{tabular} \\
\hline
\end{tabular}

Fonte: Scientific Electronic Library (SCIELO), Literatura Latino-Americana e do Caribe em Ciências da Saúde (LILACS) e Medical Literature Analysis and Retrieval System on-line (MEDLINE) - anos de 2012 a 2017.

Diante das análises dos achados da pesquisa, nesta categoria foi possível constatar que a educação permanente se mostra como uma união de práticas pedagógicas determinada a modificar a formação e atenção à saúde. Tornando-se de grande importância para conseguir uma melhora no desenvolvimento profissional, onde a aprendizagem no trabalho fortalece 
as práticas de atenção à saúde, com base nas necessidades de saúde da população (CELEDÔNIO et al., 2012).

Segundo Laprovita et al. (2016), no que diz respeito ao serviço de atendimento préhospitalar móvel, este faz parte de um espaço de grandes possibilidades para a incorporação da educação permanente, pois neste campo não deve ser feito procedimentos automáticos sem reflexões, questionamentos e entendimentos e sim saber o porquê de se estar fazendo tal evitando possíveis sequelas decorrente de imperícia, imprudência e negligência.

De acordo com Celedônio et al. (2012), a proposta da EPS é desenvolver profissionais críticos, com capacidade de aprender, de saber trabalhar em equipe e diante da realidade local da qual vivemos. Laprovita et al. (2016), expressa ainda que incorporar ensino e aprendizado ao cotidiano das instituições de ensino ao cenário real da população, consiste em um dos pontos essenciais da PNEPS.

Inclusive, considera-se que os polos de EPS, apresentam-se como meios de transformações das práticas de educação e trabalho em saúde, a fim de, trabalhar o princípio da integralidade nos serviços, e diante disso, construir uma união entre setores para capacitar profissionais para a saúde da população (CELEDÔNIO et al., 2012).

Segundo Peduzzi e Schraiber (2012, p. 3) "processo de trabalho em saúde" é "uma dimensão microscópica do cotidiano do trabalho em saúde, ou seja, à prática dos trabalhadores/profissionais de saúde inseridos no dia-a-dia da produção e consumo de serviços de saúde".

Farah (2015, p. 8) completa que:

\begin{abstract}
A finalidade do trabalho da enfermagem é o cuidado com o indivíduo, família e comunidade e ao executá-lo podemos desenvolver todas as dimensões do cuidado Assistir, Administrar, Educar, Pesquisar e Participar Politicamente isoladamente cada um deles ou concomitante, podemos dizer que a enfermagem possui mais de um processo de trabalho, desempenhado por mais de um agente (equipe de enfermagem).
\end{abstract}

Portanto, é de extrema relevância que os municípios do Brasil, foquem a atenção para o processo de trabalho dos profissionais de saúde, envolvendo-os em atividades e 
cronogramas de atualização para fortalecer a aprendizagem significativa, levando em consideração os conhecimentos e experiências prévias adquiridos por cada membro da equipe.

\section{Categoria 2: As Estratégias e Atividades de Educação Permanente em Saúde.}

Esta categoria foi evidenciada em 4 (quatro) estudos, correspondendo à 44,44\% do total, sendo estes descritos na tabela 2.

Conforme El Hetti et al. (2013), a aplicação da educação permanente saúde no fazer diário dos trabalhadores do serviço de urgência e emergência torna-se uma estratégia desafiadora uma vez que não é vista como ponto fundamental para qualificação e aperfeiçoamento dos atendimentos realizados por esta equipe. Faz-se necessário entender e aceitar que o campo de trabalho também pode e dever ser um local de aprendizagem.

Tabela 2: caracterização dos estudos sobre "As estratégias e atividades de educação permanente em saúde".

\begin{tabular}{|c|c|c|c|c|c|}
\hline $\begin{array}{c}\text { ARTIGO/ } \\
\text { AUTOR }\end{array}$ & PERIÓDICO & ANO & $\begin{array}{c}\text { TIPO DE } \\
\text { PESQUISA }\end{array}$ & OBJETIVOS & RESULTADOS \\
\hline $\begin{array}{l}\text { Educação } \\
\text { permanente em } \\
\text { Saúde: } \\
\text { metassíntese. } \\
\text { MICCAS, F. L.; } \\
\text { BATISTA S. H. S. S. }\end{array}$ & $\begin{array}{l}\text { Scientific } \\
\text { Electronic } \\
\text { Library } \\
\text { (SCIELO) }\end{array}$ & 2014 & $\begin{array}{l}\text { Revisão de } \\
\text { Literatura }\end{array}$ & $\begin{array}{l}\text { Realizar metassíntese da } \\
\text { literatura sobre os } \\
\text { principais conceitos e } \\
\text { práticas relacionados à } \\
\text { educação permanente } \\
\text { em saúde. }\end{array}$ & $\begin{array}{l}\text { A articulação educação } \\
\text { e saúde encontra-se } \\
\text { pautada tanto nas } \\
\text { ações dos serviços de } \\
\text { saúde, quanto de } \\
\text { gestão e de instituições } \\
\text { formadoras. }\end{array}$ \\
\hline $\begin{array}{l}\text { Educação } \\
\text { permanente/conti } \\
\text { nuada como } \\
\text { estratégias de } \\
\text { gestão no Serviço } \\
\text { de Atendimento } \\
\text { Móvel de } \\
\text { Urgência. EL } \\
\text { HETTI, L. B.; } \\
\text { BERNARDES, A.; } \\
\text { GABRIEL, C. S.; } \\
\text { FORTUNA, C. M.; } \\
\text { MAZIERO, V. G. }\end{array}$ & $\begin{array}{l}\text { Biblioteca } \\
\text { Virtual em } \\
\text { Saúde - BVS / } \\
\text { Literatura } \\
\text { Latino- } \\
\text { Americana e do } \\
\text { Caribe em } \\
\text { Ciências da } \\
\text { Saúde- LILACS }\end{array}$ & 2013 & $\begin{array}{l}\text { Estudo } \\
\text { Qualitativo }\end{array}$ & $\begin{array}{l}\text { Analisar a percepção dos } \\
\text { profissionais sobre } \\
\text { educação permanente } \\
\text { e/ou continuada no } \\
\text { Serviço de Atendimento } \\
\text { Móvel de Urgência de } \\
\text { um município do } \\
\text { interior do Estado de São } \\
\text { Paulo - Brasil. }\end{array}$ & $\begin{array}{l}\text { Revelaram que a } \\
\text { educação permanente } \\
\text { ainda é incipiente } \\
\text { nesse serviço. } \\
\text { Ausência de uso de } \\
\text { protocolos, } \\
\text { comunicação ineficaz, } \\
\text { falha na supervisão, } \\
\text { falta de capacitação } \\
\text { para o atendimento a } \\
\text { pacientes } \\
\text { psiquiátricos, carência } \\
\text { de humanização e falta } \\
\text { de apoio psicológico } \\
\text { aos profissionais são } \\
\text { apontados como } \\
\text { problemas a serem } \\
\text { resolvidos. }\end{array}$ \\
\hline
\end{tabular}




\begin{tabular}{|c|c|c|c|c|c|}
\hline $\begin{array}{l}\text { Educação } \\
\text { permanente, } \\
\text { continuada e em } \\
\text { serviço: } \\
\text { desvendando seus } \\
\text { conceitos. } \\
\text { PEIXOTO, L. S.; } \\
\text { GONÇALVES, L. C.; } \\
\text { COSTA, T. D.; } \\
\text { TAVARES, C. M. M.; } \\
\text { CAVALCANTI, A. C. } \\
\text { D.; CORTEZ, E. A. }\end{array}$ & $\begin{array}{l}\text { Scientific } \\
\text { Electronic } \\
\text { Library } \\
\text { (SCIELO) }\end{array}$ & 2013 & $\begin{array}{l}\text { Revisão } \\
\text { Integrativa da } \\
\text { Literatura }\end{array}$ & $\begin{array}{l}\text { Discutir os conceitos de } \\
\text { Educação Permanente, } \\
\text { Educçãão Continuada e } \\
\text { Educação em Serviço e } \\
\text { como estes conceitos se } \\
\text { relacionam }\end{array}$ & $\begin{array}{l}\text { Muitos são os } \\
\text { conhecimentos } \\
\text { produzidos acerca dos } \\
\text { processos de Educação } \\
\text { Permanente, } \\
\text { Continuada e em } \\
\text { Serviço, e que seus } \\
\text { conceitos são } \\
\text { claramente diferentes, } \\
\text { porém apresentam um } \\
\text { caráter complementar } \\
\text { e não excludente a } \\
\text { cada prática. } \\
\text { Entretanto apesar de } \\
\text { serem baseados em } \\
\text { metodologias } \\
\text { diferentes, existem } \\
\text { conflitos ao conceituar } \\
\text { cada um desses } \\
\text { processos educativos. }\end{array}$ \\
\hline $\begin{array}{l}\text { Enfermeiros do } \\
\text { serviço de } \\
\text { atendimento } \\
\text { móvel de } \\
\text { urgência: } \\
\text { Perfil e atividades } \\
\text { desenvolvidas. } \\
\text { LUCHTEMBERG, } \\
\text { M.N.; PIRES, D. E. P. }\end{array}$ & $\begin{array}{l}\text { Scientific } \\
\text { Electronic } \\
\text { Library } \\
\text { (SCIELO) }\end{array}$ & 2016 & $\begin{array}{l}\text { Estudo } \\
\text { Exploratório } \\
\text { Descritivo. }\end{array}$ & $\begin{array}{l}\text { Caracterizar o perfil e } \\
\text { identificar as atividades } \\
\text { desenvolvidas pelos } \\
\text { enfermeiros do SAMU } \\
\text { em um estado da região } \\
\text { sul do Brasil. }\end{array}$ & $\begin{array}{l}\text { As ações de cuidado } \\
\text { são o foco principal } \\
\text { das atividades dos } \\
\text { enfermeiros, } \\
\text { predominando o } \\
\text { atendimento ao } \\
\text { prescrito } \\
\text { institucionalmente } \\
\text { sem uso de } \\
\text { instrumental como a } \\
\text { SAE que poderia } \\
\text { contribuir para maior } \\
\text { visibilidade do seu } \\
\text { trabalho profissional. }\end{array}$ \\
\hline
\end{tabular}

Fonte: Scientific Electronic Library (SCIELO), Literatura Latino-Americana e do Caribe em Ciências da Saúde (LILACS) e Medical Literature Analysis and Retrieval System on-line (MEDLINE) - anos de 2012 a 2017.

Quando às estratégias e atividades de educação permanente em saúde, utilizadas em serviço, os estudos apontam que há uma falta de capacitação e conhecimento das práticas que envolvam a EPS, tanto por parte dos educadores quanto dos educandos. Levando a uma falha no processo ensino aprendizagem do profissional. Sendo que, para os profissionais atuarem nos Serviços de Atendimento Pré-Hospitalar Móvel estes devem ser habilitados pelos Núcleos de Educação em Urgências (NEU), onde seu objetivo e promover programas de formação e educação (LUCHTEMBER e PIRES, 2016).

Existe uma confusão entre os profissionais acerca das vertentes e modelos utilizados como método para abordar a EPS. Segundo El Hetti et al. (2013, p. 980): 
Os diferentes profissionais não distinguem corretamente os conceitos de "educação permanente" e "educação continuada", o que certamente dificulta a implantação de qualquer estratégia que contemple as Políticas Ministeriais de incentivo à educação permanente em saúde.

Existem vários conceitos para Educação Continuada, não há um único autor ou uma única literatura. Porém, Barbosa (2014, p. 39-40) adota a definição da Organização PanAmericana da Saúde (OPAS), sendo: “A Educação Continuada um processo permanente que se inicia após a formação básica e está destinada a atualizar e melhorar a capacidade de uma pessoa ou grupo, frente as evoluções técnicas-cientificas e as necessidades sociais".

Já a educação permanente segundo El Hetti et al. (2013), tem como objetivo principal operar na experiência dos trabalhadores juntamente com a obtenção de novos conhecimentos a partir da realidade de cada serviço. Sendo os gestores responsáveis por viabilizar ações educacionais para os profissional, aperfeiçoando-os para que desenvolvam de forma mais abrangente, significativa e qualificada suas atividades, causando efetiva transformação no seu modo de ser, agir e pensar.

Para Luchtemberg e Pires (2016), as ações de gerência e educação, voltados ao trabalho da enfermagem, mostram-se escassa. Observando que um investimento na qualificação voltada para as mesmas poderia contribuir para uma valorização e visibilidade do trabalho do profissional do SAMU e de outros setores de saúde.

Um conjunto de elementos que vai desde a metodologia, educação às instituições formadoras, são cobertas por dificuldades que está ligada a falta de investimento, infraestrutura, disponibilidade e rotatividade de profissionais, para desenvolver ou continuar a aplicação da educação permanente. Para se atingir as metas e propostas das OPAS/OMS e Ministério da Saúde, precisa-se realizar proposta de EPS com profissionais de serviço e instituições de ensino (MICCAS e BATISTA, 2014).

Ressaltando que as estratégias da EPS nos atendimentos de urgência, os treinamentos, as capacitações e as trocas de experiências devem passar por um processo de reflexão, cuja esta promoverá a identificação dos problemas encontrados na realidade e assim será traçado meios de trabalhar e transformar o serviço. Assim, enfatizando também a importância desta transformação para os profissionais bem como para a população que será melhor assistida em termos de qualidade no atendimento (COELHO et al., 2013). 
Logo, uma das contribuições da educação permanente é o leque de oportunidade e aperfeiçoamento das habilidades diante de diversas situações existentes no cotidiano que precisam de conhecimento cientifico e prático atualizado, estes aperfeiçoamentos podem ser viabilizados através de grupos de estudos, rodas de conversas, simulados realísticos, no próprio ambiente de trabalho.

\section{Categoria 3: A Percepção dos Profissionais sobre o Processo de Educação Permanente no SAMU.}

Esta categoria foi evidenciada em 03 (três) estudos, correspondendo à 33,33 \% do total, sendo estes descritos na tabela 3.

Os profissionais do SAMU percebem e valorizam a educação permanente e a descrevem como um instrumento importante no processo de melhoria das práticas em saúde no ambiente de trabalho (COELHO et al., 2013).

Tabela 3: caracterização dos estudos sobre "A percepção dos profissionais sobre o processo de educação permanente no SAMU".

\begin{tabular}{|c|c|c|c|c|c|}
\hline $\begin{array}{l}\text { ARTIGO/ } \\
\text { AUTORES }\end{array}$ & PERIÓDICO & ANO & $\begin{array}{c}\text { TIPO DE } \\
\text { PESQUISA }\end{array}$ & OBJETIVOS & RESULTADOS \\
\hline $\begin{array}{c}\text { Educação } \\
\text { permanente em } \\
\text { saúde na atenção } \\
\text { básica: percepção } \\
\text { dos gestores } \\
\text { municipais de } \\
\text { saúde. SILVA, L. A. } \\
\text { A.; SODER, R. M.; } \\
\text { PETRY, L.; } \\
\text { OLIVEIRA, I. C. }\end{array}$ & $\begin{array}{l}\text { Scientific } \\
\text { Electronic } \\
\text { Library } \\
\text { (SCIELO) }\end{array}$ & 2017 & $\begin{array}{c}\text { Pesquisa } \\
\text { qualitativa, } \\
\text { descritiva e } \\
\text { exploratória. }\end{array}$ & $\begin{array}{l}\text { Conhecer as estratégias } \\
\text { de educação em saúde } \\
\text { preconizadas e } \\
\text { desenvolvidas aos } \\
\text { trabalhadores da atenção } \\
\text { básica pelos gestores. }\end{array}$ & $\begin{array}{l}\text { Demonstram uma } \\
\text { realidade que precisa } \\
\text { ser transformada por } \\
\text { todas as pessoas } \\
\text { envolvidas no } \\
\text { processo de trabalho } \\
\text { em saúde: docentes e } \\
\text { discentes, usuários, } \\
\text { membros dos } \\
\text { conselhos de saúde, } \\
\text { trabalhadores e } \\
\text { gestores. } \\
\text { Realisticamente, } \\
\text { buscam-se } \\
\text { transformações nos } \\
\text { serviços para que se } \\
\text { qualifique a } \\
\text { integralidade da } \\
\text { atenção em saúde. }\end{array}$ \\
\hline $\begin{array}{l}\text { Percepção dos } \\
\text { profissionais de } \\
\text { saúde da atenção } \\
\text { primária sobre }\end{array}$ & $\begin{array}{l}\text { Revista de } \\
\text { Políticas } \\
\text { Públicas - }\end{array}$ & 2016 & $\begin{array}{c}\text { Estudo } \\
\text { exploratório e } \\
\text { descritivo } \\
\text { com }\end{array}$ & $\begin{array}{l}\text { Analisar a percepção dos } \\
\text { profissionais da APS em } \\
\text { Arneiroz sobre a } \\
\text { educação permanente em }\end{array}$ & $\begin{array}{l}\text { Mostraram que os } \\
\text { profissionais } \\
\text { entrevistados não } \\
\text { apresentam } \\
\end{array}$ \\
\hline
\end{tabular}




\begin{tabular}{|c|c|c|c|c|c|}
\hline $\begin{array}{c}\text { educação } \\
\text { permanente em } \\
\text { saúde. CARVALHO, } \\
\text { T. G. S.; ALMEIDA, } \\
\text { A. M. B.; BEZERRA, } \\
\text { M. I. C. }\end{array}$ & SANARE & & $\begin{array}{l}\text { abordagem } \\
\text { qualitativa. }\end{array}$ & $\begin{array}{l}\text { saúde e sua aplicação na } \\
\text { prática do serviço. }\end{array}$ & $\begin{array}{l}\text { conhecimento claro e } \\
\text { conciso referente ao } \\
\text { tema educação } \\
\text { permanente em } \\
\text { saúde, percebendo-o, } \\
\text { em síntese, como } \\
\text { educação em saúde, } \\
\text { tanto referente à } \\
\text { prática profissional } \\
\text { como à própria } \\
\text { conceituação, } \\
\text { restringindo o tema a } \\
\text { uma das atividades, } \\
\text { apresentando } \\
\text { variação de relevância } \\
\text { de acordo com o nível } \\
\text { de escolaridade. }\end{array}$ \\
\hline $\begin{array}{c}\text { Educação } \\
\text { permanente em } \\
\text { saúde: } \\
\text { experiência dos } \\
\text { profissionais do } \\
\text { serviço de } \\
\text { atendimento } \\
\text { móvel de } \\
\text { urgência. COELHO, } \\
\text { G.M.P.; ABIB, S.C.V.; } \\
\text { LIMA, K.S.B.; } \\
\text { MENDES, R.N.C.; } \\
\text { SANTOS, R.A.A.; } \\
\text { BARROS, A.G. }\end{array}$ & $\begin{array}{l}\text { Enfermagem } \\
\text { em Foco }\end{array}$ & 2013 & $\begin{array}{c}\text { Estudo } \\
\text { descritivo, de } \\
\text { natureza } \\
\text { qualitativa. }\end{array}$ & $\begin{array}{l}\text { Descrever a experiência } \\
\text { da Educação Permanente } \\
\text { em Saúde vivenciada } \\
\text { pelos profissionais de } \\
\text { saúde de um serviço pré- } \\
\text { hospitalar móvel de } \\
\text { urgência. }\end{array}$ & $\begin{array}{l}\text { O núcleo de educação } \\
\text { do serviço não se } \\
\text { encontra implantado } \\
\text { e a sobrecarga de } \\
\text { trabalho foi apontada } \\
\text { como um desafio para } \\
\text { a consolidação. }\end{array}$ \\
\hline
\end{tabular}

Fonte: Scientific Electronic Library (SCIELO), Literatura Latino-Americana e do Caribe em Ciências da Saúde (LILACS) e Medical Literature Analysis and Retrieval System on-line (MEDLINE) - anos de 2012 a 2017.

Por meio dos artigos analisados no que concerne à esta categoria foi possível identificar que os gestores e profissionais de saúde, são desconhecedores da PNEPS.

Conforme Silva et al. (2017), quanto aos gestores municipais, fica evidente a falta de conhecimento e valorização acerca das estratégias de educação permanente que são recomendadas e/ou desenvolvidas para os trabalhadores. A EPS não é vista como tática de transformação efetiva no processo de trabalho, não valorizando os ministérios e deixando de obter resultados fidedignos.

Os gestores são compostos por profissionais de diversas áreas, desde formações mais distintas até profissionais sem uma formação específica, o que não permite distinguir as peculiaridades entre as propostas educativas, reforçando o não conhecimento da PNEPS e sua importância como proposto de gestão (SILVA et al., 2017). 
"Os profissionais que apresentaram maior proximidade com o tema foram os residentes em Saúde da Familia e Comunidade, preceptores da residência multiprofissional em saúde no município, estes refletem a riqueza dos conhecimentos construídos durante esse processo." (CARVALHO, ALMEIDA e BEZERRA, 2016, p.101).

De acordo com Silva et al. (2017), é insuficiente a participação dos profissionais de saúde em programações de EPS. A escassa participação está vinculada ao insignificante número de trabalhadores e a dificuldade em conciliar seus horários de expediente para participar das atividades educativas. Contudo, há outras razões que contribuem, como a desvalorização das atividades, tendo-as como alheias a realidade do processo de trabalho.

Segundo o autor, não há políticas que permitem o acesso a PNEPS, lembrando também a exígua literatura, fazendo com que os trabalhadores de saúde desconhecem os princípios e diretrizes da mesma (CARVALHO, ALMEIDA e BEZERRA, 2016).

Entre os profissionais envolvidos e que conhecem a EPS, estes demonstram motivação e interesse diante das diversas formas de capacitação e treinamentos presentes no serviço. Foi possível ainda reconhecer que é unânime entre os profissionais que atuam no SAMU as mudanças nas atividades diárias (COELHO et al., 2013).

Sendo assim, pode-se observar que o cotidiano dos profissionais, assim como seus vícios de trabalho, pode ser modificado para uma melhor atuação destes, bem como, obter novas formas de promoção de bem-estar tanto pessoal quanto aos usuários das organizações de saúde.

\section{DISCUSSÃO}

Laprovita et al. (2016), afirma que o serviço de atendimento pré-hospitalar móvel é um importante espaço para a implantar as ações de educação permanente, visto que é um espaço da qual visa atender diversas peculiaridades com envolvimento de vários profissionais. Com a implementação da EPS, relacionando teoria e prática de acordo com a realidade local, tem se por finalidade a melhora da qualidade do atendimento oferecido, considerando os anos de trabalho e o refinamento das práticas destes profissionais. 
Os autores estabelecem uma relação à dificuldade que os profissionais têm de conceituar a educação permanente, reforçando a necessidade de revisão e divulgação dos diferentes conceitos de estratégias oferecidos. Inclusive, Silva et al. (2017) cita que os até os gestores desconhecem ou não sabem valorizar este instrumento de renovação no ambiente de trabalho.

Segundo El Hetti et al. (2013), para que a EPS seja de fato incorporada, é necessário que os ambos, tanto gestores como os trabalhadores compreendam o real conceito de educação permanente e qual sua proposta para qualificar o serviço. O que se ver é muitas aulas educativas sobre os atendimentos de urgência e emergência, mas que não se adapta à realidade local.

Sendo assim, quando oferecidos capacitações relacionados a EPS, a falta de conhecimento sobre o mesmo faz com que os profissionais venham a menosprezar esse importante instrumento, por não saberem seu objetivo e finalidade (CARVALHO, ALMEIDA e BEZERRA, 2016).

Entretanto, Silva et al. (2017) aponta ainda que entre os fatores que fragilizam a implantação dos programas de EPS, estão à falta de apoio de instituições, a falta de comunicação com a equipe e a falta de comprometimento dos profissionais com as mudanças.

Logo, um estudo da qual envolveu uma equipe multidisciplinar, registrou que os principais limitadores da implantação de uma proposta de EPS são um conjunto de consequências interligadas entre si, como: o emprego duplicado atrelado a falta de tempo, a indisponibilidade de horário, ao cansaço, ao excesso de tarefas, a remuneração inadequada e falta de incentivos. A principal proposta para se amenizar esses limitadores são principalmente o dimensionamento adequado dos profissionais juntamente com uma melhor organização do local de trabalho (SILVA et al., 2017).

Ressaltando que existe pontos facilitadores para esta incorporação, dentre eles estão o ganho de novos saberes, novas propostas educativas, a correção dos problemas encontrados no dia a dia, a interação em entre profissionais de diversos setores para juntos trocar suas experiências teórica e prática, e sobretudo ainda, mudanças no próprio ambiente de trabalho, tornando estas verdadeiras inspirações contínuas de aprendizagem (SILVA et al., 2017).

Cabe aos profissionais de enfermagem dentre as suas habilidade e competências que 
este no âmbito da educação permanente deve-se saber abordar o paciente e comunica-se, trabalhar em equipe, ter iniciativa, ter uma organização pessoal e profissional, fundamentar argumentos e decisões no ambiente de trabalho e utilizar com fluência a tecnologia disponível. Incluindo a "resiliência, respeito, vínculo e comprometimento como atitudes fundamentais aos profissionais de saúde, face à complexidade do modelo de cuidado em saúde". (SALUM E PRADO, 2014, p. 307)

Afirmam ainda, que os profissionais dão maior importância a dimensão técnica, sendo esta que indica "a maneira ou habilidade especial de executar ou fazer algo".

Na saúde, esta dimensão está relacionada:

À realização correta de técnicas e procedimentos de enfermagem para que se efetive um cuidado seguro e de qualidade, como aquelas voltadas para o controle de infecção hospitalar e biossegurança, feridas, parada cardiorrespiratória, monitorização da glicemia, entre outras, no sentido de obter informações acerca das inovações que sustentam o desenvolvimento de um trabalho com qualidade. (SALUM E PRADO, 2014, p. 304)

No Brasil, já pode ser visto polos de EPS com participação de instituições, profissionais e gestores. Porém, a falta de investimentos, falta de compromisso dos gestores e a dificuldade de construir atividades ágeis de trabalho resultam na dificuldade de construção de espaços próprios para tal. Isso está ligado também ao fato dos profissionais não participarem dos planejamentos e atualizações no ambiente (MICCAS e BATISTA, 2014).

Luchtemberg e Pires (2016), abordam sobre um dado importante relacionado aos profissionais enfermeiros que entram para o SAMU, diz que estes por trabalharem com atividades complexas, requerem uma formação especial além da graduação. Pois, tratam de situações inesperadas e que precisam de habilidades práticas e teórica para um bom desfecho do trabalho. Da mesma forma citam Carvalho, Almeida e Bezerra (2016), que o processo de educação permanente em saúde e as experiências dos profissionais do SAMU, é de grande importância a melhoria das práticas.

Deste modo, A EPS é uma das estratégias mais uteis para qualificar os trabalhadores, contribuindo na valorização e satisfação dos profissionais sendo também um precioso instrumento no aprimoramento do processo de trabalho (SILVA et al., 2017). 


\section{CONSIDERAÇÕES FINAIS}

Diante dos artigos analisados concluiu-se que, a EPS utiliza-se de mecanismo que instigam o pensamento crítico acerca das práticas do processo de trabalho, ocasionando assim transformações significativas e reorganização do processo de trabalho como um todo, desde uma conduta individual até o trabalho em equipe.

Ressalta-se ainda que na realidade do Serviço de Atendimento Móvel de Urgência a implantação da EPS torna-se difícil pois é indispensável que os profissionais tenham conhecimento abrangente e direcionada para a realidade. Pois, na vivência do ambiente de trabalho, será necessário lidar com diversos tipos de agravos, como de natureza clínica, obstétrica e traumática, com paciente de qualquer faixa etária e em qualquer tipo de ambiente, e esta realidade nem sempre será correspondente a área de formação do profissional.

Durante as análises dos dados estes indicam ainda há uma dificuldade em diferenciar conceitos de determinadas estratégias de capacitação voltado para os trabalhadores da saúde ou até mesmo nem sequer saber que existem. Também da falta de tempo em conciliar trabalho e capacitação, pela escassez de trabalhadores nos setores e falta de conhecimento sobre Educação Permanente pelo próprio gestor responsável.

Dessa maneira, foi possível atender aos objetivos da pesquisa, notando que os profissionais podem utilizar mecanismos importantes e mais eficazes para sua atuação multiprofissional e interdisciplinar, assim ocasionando mudanças na realidade do serviço prestado a sociedade e que através da EPS os profissionais da saúde passam a rever suas condutas e práticas de atuação, sendo possível compreender sua inserção no mercado de trabalho no processo de trabalho aprendizagem.

Assim, pode-se propor para os gestores locais de saúde do município e instituições de saúde pública, a importância de incorporar a Educação Permanente em Saúde no Serviço de Atendimento Móvel de Urgência, fundamentado nas portarias do Ministério da Saúde, nos princípios e diretrizes do SUS e nas normativas do COFEN, ressaltando e valorizando a educação permanente em serviço através de práticas voltadas para a realidade de cada local de serviço.

Salienta-se que houve dificuldade de encontrar artigos científicos atualizados da qual 
abordasse a educação permanente em saúde no Serviço de Atendimento Móvel de Urgência. Recomenda-se que seja feito mais estudos sobre EPS pela importância que a mesma propõe aos serviços, tanto para o aprimoramento profissional bem como para proporcionar aos usuários do serviço, uma assistência livre de danos decorrentes de imperícia, imprudência ou negligência.

\section{REFERÊNCIAS}

BOTELHO, L. L. R.; CUNHA, C. C. A.; MACEDO, M., o método da revisão integrativa nos estudos organizacionais. Belo Horizonte: Gestão e Sociedade, 2011. v. 5, n. 11, p. 121-136, mai/ago. Disponível em: <https://www.gestaoesociedade.org/gestaoesociedade/article/view/1220/906>. Acesso em: 23 set. 2017.

BRASIL. Ministério da Saúde. Constituição (2004). Portaria $\mathbf{n}^{0}$ 198, de 13 de fevereiro de 2004. Política Nacional de Educação Permanente em Saúde Como Estratégia do Sistema Único de Saúde. Disponível em: <https://www.nescon.medicina.ufmg.br/biblioteca/imagem/1832.pdf>. Acesso em: 11 abr. 2017.

. Ministério da Saúde. Constituição (2007). Portaria no 1.996, de 20 de agosto de 2007. Dispõe sobre as diretrizes para a implementação da Política Nacional de Educação Permanente em Saúde. Disponível em: <http://bvsms.saude.gov.br/bvs/saudelegis/gm/2007/prt1996_20_08_2007.html>. Acesso em: 11 abr. 2017.

. Ministério da Saúde. Constituição (2003). Portaria no 1.864, de 29 de setembro de 2003. Componente Pré-hospitalar Móvel da Política Nacional de Atenção às Urgências. Disponível em: <http://bvsms.saude.gov.br/bvs/saudelegis/gm/2003/prt1864_29_09_2003.html>. Acesso em: 15 abr. 2017.

--_-_-. Ministério da Saúde. Constituição (2012). Resolução no 466, de 12 de dezembro de 2012. Conselho Nacional de Saúde. Brasil. Disponível shttp://bvsms.saude.gov.br/bvs/saudelegis/cns/2013/res0466_12_12_2012.html>. Acesso em: 16 abr. 2017.

. Ministério da Saúde. Cartilhas da política nacional de humanização acolhimento nas práticas de produção de saúde / Secretaria de Atenção à Saúde, Núcleo Técnico da Política Nacional de Humanização. - 2. ed. 5. Brasília: Editora do Ministério da Saúde, 2010. Disponível em: $\leq h \mathrm{ttp}$ ://bvsms.saude.gov.br/bvs/publicacoes/caderno_textos_cartilhas_politica_humanizacao.pdf>. Acesso em: 18 abr. 2017.

. Ministério da Saúde. O que é o SAMU 192? / Portal da Saúde. Brasília, 2014. Disponível em: shttp://portalsaude.saude.gov.br/index.php/o-ministerio/principal/secretarias/951-sas-raiz/dahuraiz/forca-nacional-do-sus/12-forca-nacional-do-sus/13407-servico-de-atendimento-movel-de-urgenciasamu-192>. Acesso em: 18 abr. 2017

. Ministério da Saúde. Portaria no 1.010, De 21 De Maio De 2012. Redefine as diretrizes para a implantação do Serviço de Atendimento Móvel de Urgência (SAMU 192) e sua Central de Regulação das Urgências, componente da Rede de Atenção às Urgências. Disponível em: < http://bvsms.saude.gov.br/bvs/saudelegis/gm/2012/prt1010_21_05_2012.html>. Acesso em: 05 jan. 2018.

BARBOSA, M. R. Educação continuada em enfermagem e a qualidade de assistência. Mestrado em enfermagem. Guarulhos, SP, Brasil: UnG, 2014. Disponível em: < http://tede.ung.br/bitstream/123456789/529/1/Marli+Reinaldo+Barbosa.pdf>. Acesso em: 05 jan. 2018.

CARVALHO, T. G. S.; ALMEIDA, A. M. B.; BEZERRA, M. I. C., Percepção dos profissionais de saúde da atenção primária sobre educação permanente em saúde. Ceará, Brasil: Sanare, Sobral. 2016 - V.15 n.02, p.94-103, Jun./Dez. Disponível em: <https://sanare.emnuvens.com.br/sanare/article/view/1043>. Acesso em: 10 out 2017. 
CELEDÔNIO, R. M.; JORGE, M. S. B.; SANTOS, D. C. M.; FREITAS, C. H. A., AQUINO, F. O. T. P., Políticas de educação permanente e formação em saúde: uma análise documental*. Fortaleza, Ceará, Brasil: Rev Rene, 2012. 13(5):1100-10. Disponível em: 〈http://www.redalyc.org/articulo.oa?id=324027984015>. Acesso em: 18 set 2017.

COELHO, G.M.P.; ABIB, S.C.V.; LIMA, K.S.B.; MENDES, R.N.C.; SANTOS, R.A.A.; BARROS, A.G, Educação permanente em saúde: experiência dos profissionais do serviço de atendimento móvel de urgência. Brasil: Enferm. Foco, 2013. 4(3,4) 161 - 163. Disponível em: <revista.portalcofen.gov.br/index.php/enfermagem/article/download/540/223>. Acesso em: 06 nov 2017.

EL HETTI, L. B.; BERNARDES, A.; GABRIEL, C. S.; FORTUNA, C. M.; MAZIERO, V. G., Educação permanente/continuada como estratégias de gestão no Serviço de Atendimento Móvel de Urgência. Ribeirão Preto, SP, Brasil: Rev. Eletr. Enf. [Internet], 2013. out/dez;15(4):973-82. Disponível em: <http://pesquisa.bvs.br/brasil/resource/pt/lil-717983>. Acesso em: 10 out 2017.

FARAH, B. F., Processo de Trabalho em Enfermagem. Juiz de Fora/MG, Universidade Federal De Juiz De Fora Faculdade De Enfermagem, 2015. Disponível em: <http://www.ufff.br/admenf/files/2015/03/processo-detrabalho-em-enfermagem-adm-I.pdf>. Acesso em: 10 fev 2018.

GALVÃO, C. M.; SAWADA, N. O.; TREVIZAN, M. A. Revisão sistemática: recurso que proporciona a incorporação das evidências na prática da enfermagem. Ribeirão Preto, SP, Brasil: Revista Latino-Americana de Enfermagem, 2004. v. 12, n. 3, p. 549-56. Disponível em: $<$ http://www.scielo.br/scielo.php?pid=S010411692004000300014\&script=sci_abstract\&tlng=pt>. Acesso em: 10 out 2017.

LAPROVITA, D.; FERNANDES F. C.; ALMEIDA L.P; CORVINO, M. P. F.; CORTEZ, E. A.; BRAGA, A. L.S., Educação permanente no atendimento pré-hospitalar móvel: perspectiva de Emerson Merhy. Niterói (RJ), Brasil: Rev enferm UFPE online, 2016. 10(12):4680-6, dez. Disponível em: shttp://pesquisa.bvs.br/brasil/resource/pt/bde-30199>. Acesso em: 10 out 2017.

LUCHTEMBERG, M.N.; PIRES, D.E.P. Enfermeiros do Serviço de Atendimento Móvel de Urgência: perfil e atividades desenvolvidas. Florianópolis, SC, Brasil: Rev Bras. Enferm [Internet], 2016. 69(2):194-201. Disponível em: $\leq$ http://www.scielo.br/pdf/reben/v69n2/0034-7167-reben-69-02-0213.pdf>. Acesso em: 10 out 2017.

MICCAS, F.L.; BATISTA, S.H.S.S., Educação permanente em saúde: metassíntese. Santos, SP, Brasil: Rev Saúde Pública, 2014. 48(1):170-185. Disponível em: $\leq h t t p: / / w w w . s c i e l o . b r / s c i e l o . p h p ? p i d=S 003489102014000100170 \&$ script=sci_abstract\&tlng=pt>. Acesso em: 10 out 2017.

PEDUZZI, M.; SCHRAIBER, L. B. Processo de Trabalho em Saúde. In: Dicionário da Educação profissional em Saúde. Rio de Janeiro: ENSP/FIOCRUZ. Disponível: http://www.epsjv.fiocruz.br/dicionario/verbetes/protrasau.html. Acesso em: 15 fev 2018.

PEIXOTO, L. S.; GONÇALVES, L. C.; COSTA, T. D.; TAVARES, C. M. M.; CAVALCANTI, A. C. D.; CORTEZ, E. A., Educação permanente, continuada e em serviço: desvendando seus conceitos. Niterói, RJ, Brasil: Rev. Eletr. Trimestral de Enfermeria, 2013. Disponível em: <http://scielo.isciii.es/pdf/eg/v12n29/pt_revision1.pdf>. Acesso em: 10 out 2017.

ROCHA, M. D. S., A importância a educação permanente para a equipe de enfermagem em um serviço de urgência e emergência. Florianópolis, SC, Brasil. Universidade Federal De Santa Catarina - Especialização Em Urgência E Emergência Em Linhas De Cuidados, 2014. Disponível em: https://repositorio.ufsc.br/bitstream/handle/123456789/173622/MARIA\%20DAN\%C3\%9ABIA\%20SANTOS\%20 DA\%20ROCHA\%20-EMG-TCC.pdf?sequence=1\&isAllowed=y. Acesso em: 22 fev 2018.

SALUM N.C.; PRADO M., A Educação Permanente No Desenvolvimento De Competências Dos Profissionais De Enfermagem. Florianópolis SC, Brasil: Texto Contexto Enferm, 2014, Abr-Jun; 23(2): 301-8. Disponível em: http://www.scielo.br/pdf/tce/v23n2/pt_0104-0707-tce-23-02-00301.pdf, Acesso em: 26 fev 2018.

SILVA, L. A. A.; SODER, R. M.; PETRY, L.; OLIVEIRA, I. C., Educação permanente em saúde na atenção básica: 
percepção dos gestores municipais de saúde. Rio Grande do Sul, Brasil: Rev Gaúcha Enferm., 2017. mar;38(1):e58779.

Disponível

em:

<http://www.scielo.br/scielo.php?pid=S198314472017000100407\&script=sci_abstract\&tlng=pt $>$. Acesso em: 10 out 2017.

SILVEIRA, R. C. C. P., O cuidado de enfermagem e o cateter de Hickman: a busca de evidências. Dissertação (Mestrado). Ribeirão Preto: Universidade de São Paulo, Escola de Enfermagem de Ribeirão Preto; 2005. Disponível em: <http://www.scielo.br/pdf/ape/v18n3/a08v18n3.pdf>. Acesso em: 10 out 2017.

SOUZA, M. T.; SILVA, M. D.; CARVALHO, R., Revisão integrativa: o que é e como fazer. Einstein (São Paulo) vol.8 no.1 São Paulo Jan/Mar. 2010. Disponível em: $\leq$ http://www.scielo.br/scielo.php?pid=S167945082010000100102\&script=sci_arttext\&tlng=pt>. Acesso em: 27 set. 2017.

URSI, E. S;GAVÃO, C. M., Prevenção de lesões de pele no perioperatório: revisão integrativa da literatura. [dissertação]. Ribeirão Preto: Universidade de São Paulo, Escola de Enfermagem de Ribeirão Preto: Rev Latinoam Enfermagem, 2006. 14(1):124-31. Disponível em: <http://www.scielo.br/pdf/rlae/v14n1/v14n1a17.pdf>. Acesso em: 10 out 2017.. 